ECONOMICS

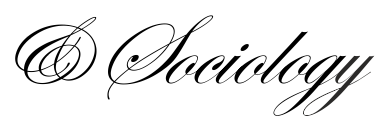

Kokthi, E., Guri, G. \& Muco, E. (2021). Assessing the applicability of geographical indications from the social capital analysis perspective: Evidences from Albania. Economics and Sociology, 14(3), 32-53. doi:10.14254/2071789X.2021/14-3/2

\title{
ASSESSING THE APPLICABILITY OF GEOGRAPHICAL INDICATIONS FROM THE SOCIAL CAPITAL ANALYSIS PERSPECTIVE: EVIDENCES FROM ALBANIA
}

\author{
Elena Kokthi \\ Agriculture University of Tirana, \\ Albania \\ E-mail:e.kok.thi@,ubt.edu.al

\section{Gert Guri \\ Department of Industrial \\ TU/e, Netherland \\ E-mail: g.guri@,tue.nl \\ Elda Muco \\ Paul Valery University, \\ Montpellier, France \\ E-mail:eldamuco94@gmail.com} \\ Engineering \& Innovation Sciences, \\ Eindhoven University of Technology
}

Received: April, 2021

1st Revision: June, 2021

Accepted: September, 2021

DOI: $10.14254 / 2071-$

789X.2021/14-3/2

\begin{abstract}
This ex-ante study explores the readiness of local stakeholders in a rural area to undertake the collective actions necessary to create a Geographical Indication on cheese to protect it from unfair competitiveness provided by brand usurpation. The paper provides an analytical model employable to assess the willingness of local stakeholders to cooperate on achieving a common goal in different post-communist rural areas. The proposed model combines operationalised, cognitive, and structural social capital indicators with Ostrom Conditions on collective action, referring to symmetric interests. Thus, it represents a methodology to realise a priori whether a local rural community is willing to undertake collective action to achieve a common objective. One hundred cheese producers were interviewed using scenario type questions. The results show that symmetric interests have the lowest effect on willingness to cooperate compared to structural social capital and demographics. The study indicates that better-educated respondents are more willing to cooperate than less well-educated. As in other post-communist countries, the educational and demographic factors can become an essential element, which may help overcome the negative perceptions of cooperation from the past.
\end{abstract}

JEL Classification: 0350, P2, P3
Keywords: willingness to cooperate, Ostrom Conditions symmetric interests, collective actions, geographical indications

\section{Introduction}

Typical agro-food or territory products well-known in the market examplify how locality can interact with the economic perspective of territory and, for this reason, typical products can become central when local actors draft and implement development strategies in rural areas (Pacciani et al., 2001; Pecqueur, 2001).In this vein, scholars argue that geographical indications $(\mathrm{GI})^{1}$ - referring in the EU legal framework to definition and

\footnotetext{
${ }^{1} \mathrm{~A}$ geographical indication (GI) is a distinctive sign used to identify a product whose quality, reputation, or other characteristic is linked to its geographical origin (EU, 2012).
} 
protection of typical local agricultural products - can become an essential vector of regional and territorial development in both developed and developing countries (Pecqueur, 2001; Rangekar, 2004). Moreover, the positive reputation of a specific local product, by offering an apparent reference to its production area, enhances the development of baskets containing other products and services of the same territory (Groote, 2009; Hirczak et al., 2008; Pacciani et al., 2001; Pecqueur, 2001; Rangekar, 2004). However, implementing development strategies around a qualitatively reputed local product, depends on whether there is interest of various stakeholders directly or indirectly involved in its valorisation (Pacciani et al., 2001; Pecqueur, 2001).

Researchers argue that European quality schemes, such as GIs, offer a mechanism to help increase the profits of local producers and their willingness to invest in local high-quality products since GIs can address unfair imitation and origin name usurpation (Kokthi et al., 2016; Kokthi \& Kruja, 2017). However, these quality schemes can become a potential instrument of protection only if producers in particular, and local stakeholders in general, cooperate and interact with public institutions to undertake the necessary steps of product valorisation (enable it to function as a GI). The conditions that allows networks of stakeholders to perform and the cooperation process to unfold - thanks to a willingness to cooperate and network among local actors - are mainly related to the concept of social capital. The latter is defined in this paper as the link by which cooperative relationships between citizens facilitate the resolution of common problems through collective actions (Brehm \& Rahn, 1997; Ostrom, 2011; Putnam, 2000; Welter, 2012).

This research will employ the conceptual framework of social capital to provide an analytical model for examining whether local stakeholders are ready to undertake collective actions in relation to Gjirokastra cheese, a highly reputed local product in south Albania. ${ }^{2}$ The paper addresses this objective by focusing on the five aspects necessary to assess the chances of this product to function as a GI, analysing: 1)whether there is a commonly shared story from local stakeholders about the product's benefits, which has GI potential; 2) if local stakeholders in this area have the social capital capacity to undertake the necessary collective actions to enable Gjirokastra Cheese to function as a GI; 3) if the awareness of being harmed, (in the case that the product does not function as a GI) can provide enough incentives among stakeholders (symmetric interests) to cooperate; 4) which component of social capital influences the propensity to cooperate, and 5) if there is a demographic effect on the propensity to cooperate. Fourresearch questions (RQ) are proposed to achieve the paper's objective:

$R Q$ 1: Is there a common narrative from the stakeholder's viewpoint that might influence the creation of a symmetric interest around a potential GI?

$R Q$ 2: Does the awareness of being harmed influence the level of cooperation (symmetric interests)?

$R Q$ 3: What component of social capital influences the willingness to cooperate?

RQ4: Do the demographics of respondents influence the willingness to cooperate?

This paper is organised into four sections to achieve its goal of understanding how stakeholder's willingness, in this case, to help promote Gjirokastra Cheese as a GI, is influenced by various factors; these include the readiness of social capital to encourage cooperation and the demographic constitution of the population. The first section examines the concept of social capital and provides an analytical model to explore the existing social capital and the willingness of local stakeholders to cooperate. The second presents the

\footnotetext{
${ }^{2}$ Beyond a great reputation among customers, the market appreciation of Gjirokastra Cheese is also expressed by a high price premium for the product's origin (Kokthi \& Kruja, 2017).
} 
methodological framework. A discussion of the field research results is presented in the third section, while conclusions are provided in the final section.

This organization highlights the paper's novelties standing on two aspects: a) the approach of conducting analysis; b) and the methodological instrument employed. Differently from other studies, which conduct an ex-post analysis to assess the economic impact of the GI application on local development. We employ an ex-ante analysis to assess whether there are opportunities for implementing the GI to stimulate local development. The combination of social capital indicators with Ostrom conditions constitutes a novel methodological instrument that can be applied to conduct such analysis in other countries with similar conditions.

\section{Literature review and analytical model}

\section{Literature review}

Few concepts in social science have generated such a variety of considerations and explanations such as the concept of social capital in such a short period. The latter has offered the opportunity to explain more thoroughly the differences in political and economic performance across states and communities by adding analysis factors, such as trust, networks, and forms of civic engagement (Helliwell \& Putnam, 1995; Putnam, 2000). From villages to international communities, the economic and political performance of societies depends to a great extent on how common problems are addressed. The theoretical relevance of social capital lies in its potential to explain mechanisms of collective and coordinated action, which fosters - in complex interrelationships - civic orientations, institutional effectiveness, and system stability (Putnam, 1993).

Contemporary scholars of social capital analyse the concept by placing the problem of collective action at the centre of political and economic discourse. According to Putnam (2000), life is easier in a community blessed with a substantial stock of social capital because 1) networks of civic engagement foster norms of generalised reciprocity; 2) encourage the emergence of social trust; 3) facilitate coordination and communication; 4) amplify reputations; and 5) embody past success at collaboration, which can serve as a cultural template for future collaboration. According to the same scholar, members of associations are much more likely than non-members to participate in politics, spend time with neighbours, and express social trust. Social trust and civic engagement are strongly correlated; the greater the density of associational membership in a society, the more trusting its citizens. Putnam's concept of social capital has three components: a) moral obligations (reciprocity, solidarity) and norms; b) social values (especially trust); c) and social networks (especially voluntary associations). In his social capital discourse, civic engagement is the main pillar of social capital because it is considered the main source to generate trust. In the same vein, Brehm and Rahn(1997)stated that there is an asymmetric relationship between civic engagement and interpersonal trust since it is probably easier for a community to generate greater levels of participation than it is for that community to install more trusting attitudes among members. Hence, with no civic engagement in place, it will be difficult to generate trust (Welter, 2012). Trust and civic engagement constitute the two facets of the same underlying factor: social capital (Brehm \& Rahn, 1997; Putnam, 2000).

In the second generation of collective action theories, various forms of social capital contribute to resolving common problems by enhancing trust among the actors. According to Bowles and Gintis (2002), societies are better off when their members cooperate to achieve common goals and view it as an efficient mechanism for ordering societal relationships, 
mainly because the market or state does not possess exhaustive private or localised information. Another component of boosting trust is state institutions since civic attitudes such as trust are most likely embedded in impartial, fair, and efficient state institutions (Rothstein \& Stolle, 2008). Trust is perceived as a direct outcome of social capital helping to foster local and territorial development (Callois, 2004; Callois \& Aubert, 2007, p. 2) but is also understood to be an element of cognitive social capital ${ }^{3}$ (Villalonga-Olives \& Kawachi, 2017; Villalonga-Olives et al., 2016; Villalonga-Olives \& Kawachi, 2015). For this reason, while making an effort to define social capital, several indicators have been proposed, and the authors distinguish two forms of social capital: i) cognitive and ii) structural social capital (Villalonga-Olives \& Kawachi, 2017). Cognitive social capital is operationalised through the level of perceptions and interpersonal trust, reciprocity, and sharing. Structural social capital is assessed through the density of social networks and pattern of civic engagement.

For our purpose, we focus on assessing the value of social capital, referring to a broader human interaction to achieve common objectives in an area such as a region and/or territory (Callois, 2004; Callois \& Aubert, 2007). Researchers argue that in areas in which social capital is well-rooted among inhabitants will be more successful in achieving proper objectives. In this, they draw upon three arguments. First, social capital means a high-density of connections, some of which transmit essential information. Information is costly, and those who have access can make balanced decisions and gain advantages

Given that information and knowledge today are numerous and fragmented, having information on new technologies, potential demand, or establishing a fruitful interaction with key partners can be crucial to regional and territorial development. Second, mechanisms of cooperation established by social capital play a positive role in creating trust in a group of people. Constant cooperation reduces opportunistic behaviour, builds trust and generates the psychological effect of individuals internalising the community's interest. Third, social relations between individuals facilitate the development of collective activities in the form of security mechanisms. Mutual assistance can be an excellent development opportunity in places where state institutions in charge of offering such services are ineffective.

The multi-dimensional framework of social capital induces scholars to employ several indicators to analyse this phenomenon. In the literature, common indicators such as civic participation, trust, bonding, bridging, and linking have been employed so far when referring to social capital regardless of its field of application such as health studies (Harpham et al., 2002; Shiell et al., 2018; Villalonga-Olives \& Kawachi, 2017; Alvarez \& Romai, 2017), environmental factors(Notaro \& Paletto, 2011; Irwin \& Berigan, 2013;Frey \& Bohnet, 1996), local/territory issues (Brehm \& Rahn, 1997;Callois, 2004;Callois\& Aubert, 2007), and the impact on developing entrepreneurship (Welter, 2012). Independent from the applied field of this concept, scholars argue that social capital is a western construct developed to understand processes within established democratic systems and warn that it might be difficult to transpose it to any country (Murray, 2005). However, the concept of social capital can be employed as an instrument for analysing of how trust is formed, and to understand cooperation amongst individuals. Considering the characteristics of our study area, we draw upon three theories considered relevant to analyse social capital in post-communist rural areas: a) rational choice theory; b) civic engagement and voluntary activity; and c) network theory (ibid). Rational choice theory is grounded in strategies of rationale, which enforces group norms in favour of cooperation with the promise of future benefits. Within this theoretical approach, trust is an essential ingredient. Civic engagement theory, based on Putnam's linear relationship, argues that higher levels of civic engagement generate greater trust, which in turn creates cooperative relationships. The theory of network analyses the

\footnotetext{
${ }^{3}$ Cognitive social capital is operationalised through the level of perception and interpersonal trust, reciprocity, and sharing.
} 
mechanism of transmitting information/knowledge amongst network members. With respect to rural areas, the network aspect of social capital has been studied in relation to cooperative farms and the privatisation of agricultural land. Gatzweilerand Hagedorn (2001) showed that certain cooperative managers progressed in the transition period due to good business practices on exploiting the potential of social capital. A wide strand of research analysing social capital in post-communist countries focuses on how macro structures brought about as the legacy of communism - i.e. collective cooperatives and state-owned farms - affected trust, reciprocity, and cooperation between individuals. This research employs an integrative approach between cooperation and social capital to understand how post-communist rural communities adapt and organise in response to a given dilemma and how the propensity or willingness to cooperate is determined by local organisation capacity. To analyse the potential of collective action and the factors influencing it, the following section details the conceptual framework employed.

\section{Conceptual framework}

Since our study is conducted in Albania, we have had to tailor the theoretical framework on social capital to mirror the characteristics of social capital in the rural area of a post-communist state. Methodological conceptualisation and assessment of social capital usually refers to the transposition of a western construct and is therefore limited in analysing the situation of social capital in post-communist contexts since it is not well equipped to consider existing social realities in these countries (Dowley \& Silver, 2002). To address this limitation and provide an analytical framework that draws upon social capital to examine the current situation in a post-communist state, this paper has endorsed Ostrom's conditions framework on collective action (Gardner et al., 1990; Ostrom, 1990, 2000, 2003). Ostrom's conditions are used in combination with the social capital approach in order to avoid the subjective interpretation of the respondent while focusing on stakeholder willingness to cooperate. In this respect, we can argue that creating a territory branding strategy such as GI calls for common actions, since this process is strongly related to the common story that the territory developed by actors around a product or service with high potential. In this case, the common challenge is often linked to the symmetric interest of local stakeholders, which arises from the perception that external factors can harm a local potential GI. This common challenge and consequent common action materialises when the following conditions are satisfied: 1) 'most stakeholders' conclude that they will be harmed if they do not adopt new rules (the erosion of willingness from regular customers to pay because of name usurpation by other producers who do not offer the same quality of product); 2) most stakeholders highly value continuing the activity, so it's worth undertaking common action as a long-term investment to protect this activity; 3) stakeholders share generalised norms of reciprocity and trust among them; and 4) stakeholders are a small and stable group. Considering that these four preconditions are satisfied among cheese producers of Gjirokastra (see Appendix, Table 3), we assume that they will be able to understand the propensity for cooperation to create a GI around their well-known cheese. The analysis of their willingness to take collective action offers the opportunity to discover whether the GI for Gjirokastra Cheese has a chance to be established now or in the future. This leads us to the first research question: Is there a common narrative from the stakeholder's viewpoint that might influence the creation of symmetric interest around a potential GI, and is the awareness of being harmed (common narrative) impacting the level of cooperation? To address this question, we offer: 1) a conceptual framework, which adapts the social-capital concept - as an overall umbrella of collective action - to the characteristics of a rural area in a post-communist country; and 2) 
the analytical model that operationalises the concepts and assesses the willingness of stakeholders in Gjirokastra to take collective action to establish the GI of Gjirokastra Cheese.

The conceptual framework adapts the metaphor of matryoshka, drawing on the methodological approach of Ostrom to identify those variables, which then will be operationalised to provide the tools for the analytical model. We begin with the assumption that it is necessary to have a common narrative around a well-reputed local product to convince institutional and local actors to undertake the steps to promote it into a GI (see figure 1). The understanding that a common narrative is created thanks to a collective action undertaken by all the interested stakeholders constitutes the first level of matryoshka. The second level examines factors that influence the rationale and willingness of stakeholders to undertake collective action (not always presented simultaneously since there are cases when stakeholders have the collective action rationale but the costs to undertake it are still higher than the opposite). At the third and final level of the conceptual framework, metaphor stands trust and reciprocity among local stakeholders and trust concerning local and/or central institutions as a precondition for creating networking and undertaking civic engaging collective actions to achieve shared objectives.

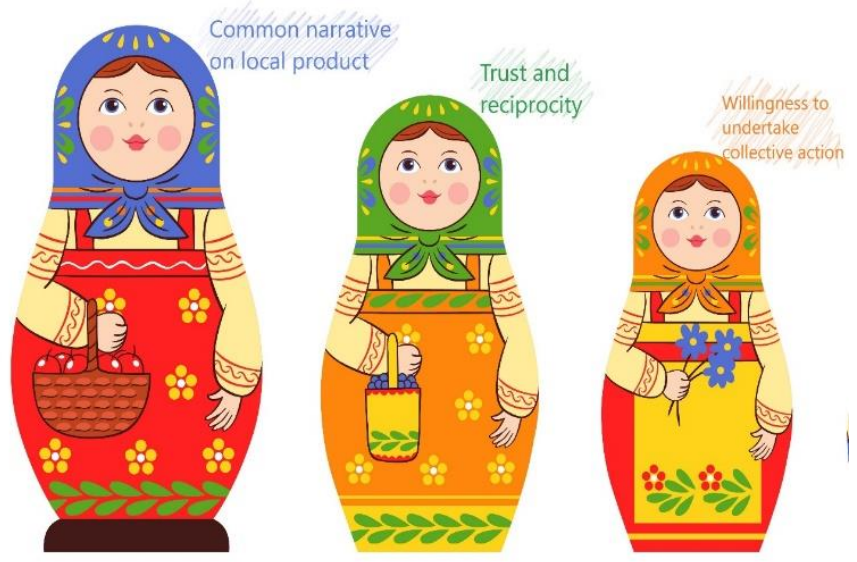

Figure 1. Metaphor of Matryoshka Source: Authors

Since the collective action undertaken by interested stakeholders is a natural consequence of the: a) willingness to cooperate; and b) trust/reciprocity among stakeholders and of the latter towards institutions, we will focus our analysis on the second and third level of the metaphor - willingness to cooperate and trust/reciprocity. The analytical model operationalises these two levels of the conceptual framework, employing three variables: 1) willingness to cooperate (dependent variable); 2) trust/reciprocity, known as cognitive, social capital (independent variable); 3) civic engagement and networking, known as structural social capital (independent variable).

To provide the conceptual framework, we will focus on those collective actions that refer to cooperation between individuals when there is result-oriented interaction at the collective level (many stakeholders) for a predetermined goal (potential GI). Such collective actions, especially at a local level, become an efficient mechanism to redirect relationships towards development opportunities when the market or state has incomplete information about local private economic activities and/or potential future economic activities (Bowles \& Gintis, 2002). However, before undertaking a set of collective actions, stakeholders should have the rationale and willingness to cooperate. For this reason, the dependent variable in this 
study is the willingness to cooperate, which is framed in the research in two questions ${ }^{4}$ : Suppose you are facing the following alternatives, which would you prefer most? a) Own and farm 5 hectares of land entirely by yourself or b) Own and farm 15 hectares of land jointly with other farmers? The selection of this dependent variable is based on conceptual issues related to the historical and social construction of cooperation in rural areas in Albania. Cooperation in rural areas during the communist period was based on the common administration of land and agriculture inputs. It is important to highlight that Albania had the largest state owned/common administrated surface area among all countries in the Western Balkans that shared the same agricultural features(Guri et al., 2011). After 40 years of common administration of land (socialist cooperative of kolkhoz type), the average income in rural areas was 32\% lower compared to urban areas (Guri, 2008). This underperformance produced a vivid rejection of cooperative or collective actions in rural areas as being inefficient and unproductive from the economic perspective. Even 30 years from the collapse of the collective administration and the establishment of small-subsistence farms (between 1 and $5 \mathrm{ha}$ ), the negative perception of cooperation with other farmers remains intense, since the willingness of rural households to cooperate is strongly impacted by history. To analyse the current situation, this research focuses on what the literature identifies as three key components for assessing the willingness to cooperate: a) solidarity and reciprocity; b) civic engagement; and c) network (Murray, 2005).

Solidarity and reciprocity are essential ingredients of social capital and influence the cooperation degree among local stakeholders, being necessary preconditions for collective actions to succeed. Willingness to help the others is operationalised in the present research by asking respondents the following question: 1) Suppose someone in the village faces an unfortunate situation (for example, their home burns down or collapses), in your opinion, who should be first called upon to help him/her? a) Family members; b) Neighbours; c) the village community; d) Local government/municipal political leaders; f) No-one. Civic engagement is also an essential indicator for cooperative behaviour since a civic community is characterised by active participation in public affairs and widespread membership in voluntary associations (Kunioka \& Woller, 1999). The analysis of civic engagement among respondents is analysed through a set of statements with two response possibilities - yes and no (see table 4).

Network the capacity of local stakeholders is analysed thanks to respondent feedback on three questions: 1) How group individuals communicate with one another; 2) How they communicate with the network, and 3) If they share knowledge or information and other inputs should be understood.

Having provided the analytical tools related to willingness to cooperate, our analysis moves on from this level of matryoshka to the final level, i.e., that of trust. To understand how trust among local stakeholders affects willingness to cooperate, the paper analyses: Which trust indicator influences willingness to cooperate among producers? We start from the agreed assumption that cooperation regarding the land is considered one of the complete types of cooperation in the farming sector, since it demands a change regarding the private property definition of land and agriculture inputs. Applying land cooperation requires fundamental changes in the farmer's mind-set and an essential stock of trust formation. Though there are many different levels and categorisations of trust (Paldam \& Svendsen, 2000), we focus in this paper on the density of trust existing within a localised group/network, which can then be extended to society as a whole. To avoid biased positive answers, even at this level of analysis, we have opted to ask trust-scenario questions:

\footnotetext{
${ }^{4}$ To avoid biased positive answers, the study analyses the willingness of farmers to cooperate not only by asking their general perception of cooperation, but placing them in a quasi-real cooperation scenario.
} 
1. Do you think people in your village trust each other to lend money? house?

2. If you had to leave the village for some time, who will you ask to take care of the

3. If you suddenly had to go away for a day or two, who could you count on to take care of your children? a) Family members (parents, brother, sister); b) Neighbours; c) Anyone from the village or neighbourhood; d) Don't have children (see further in Appendix, Table 3).

Once the conceptual framework is constructed, in terms of different interacting levels to create the common narrative and undertake the actions necessary to establish a GI (the metaphor of matryoshka), and the indicators employed to operationalise the concepts characterising each level are provided, the paper can then frame the analytical model of this study. The operationalising indicators considered in this study are:

Willingness to cooperate (dependent variable);

Structural social capital operationalised through civic engagement and network capacity among local stakeholders (independent variable);

Cognitive social capital operationalised through: solidarity, reciprocity, informal trust, trust in other local stakeholders (radius of trust), and trust in central and local institutions (independent variable).

Figure 2 schematically presents the analytical model incorporating dependent and independent variables - broken-down in the operationalised framework - with the necessary symmetric preconditions to convince stakeholders to undertake collective action in relation to establishing a GI for Gjirokastra Cheese.

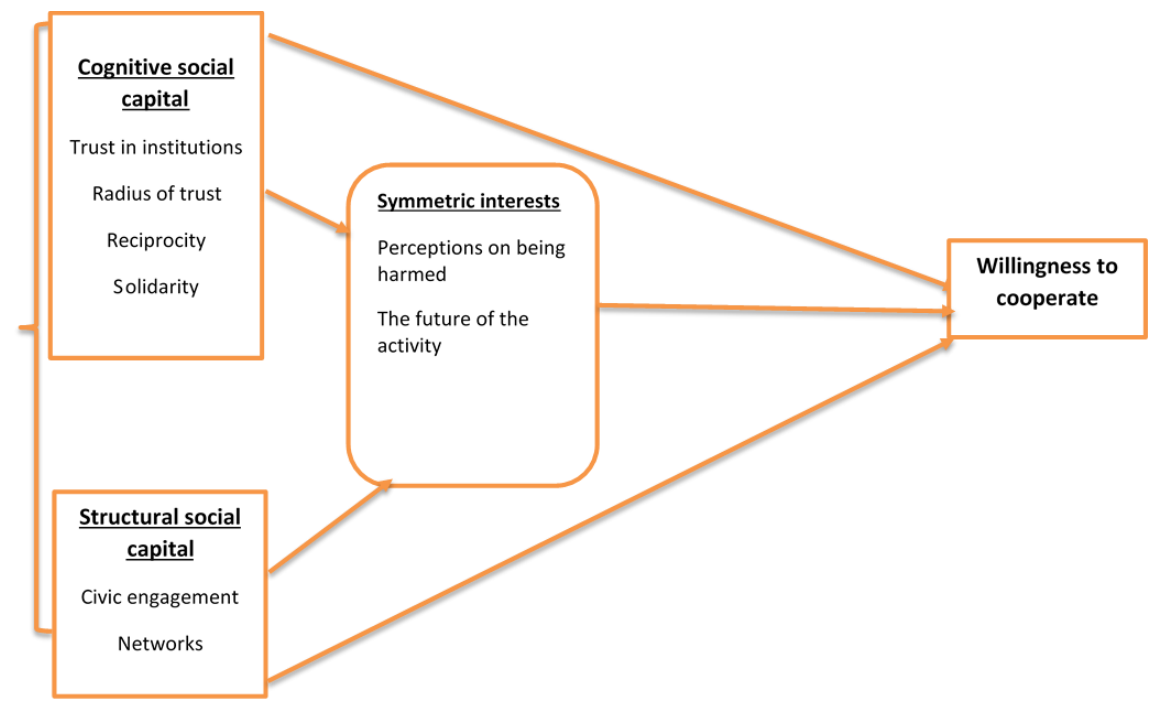

Figure 2. An integrative approach to measure the willingness to cooperate

Source: Adapted from Ostrom (2009)

\section{Methodological approach}

\section{Research instrument}

Social capital is a complex concept, and questions may generate misunderstandings among respondents, especially in rural areas where farmers prefer not to express personal problems by avoiding directed questions where possible. For this reason, we have opted for a closed structured questionnaire. The latter was organised into three sections. The majority of 
questions were constructed as scenarios ${ }^{5}$ to avoid biased answers; this was achieved by placing the respondent in a specific situation and asking how they would have behaved. Each section provides questions about different indicators used to operationalise the social capital and symmetric interests (cognitive, structural, and cooperation). The first section encompasses questions related to cognitive social capital such as solidarity, reciprocity, cooperation, trust, and the radius of trust. In the second section, questions dealing with structural social capital are unravelled, as presented in table 4. In this section, civic engagement, networks, collective actions, and future collective actions indicators are considered. The third section presents questions that mirror Ostrom's conditions, adapted for this study and presented in table 4 .

\section{Sampling}

This study was carried out in four administrative communes/units of the municipality of Gjirokastra in December 1019-January 2020. Random sampling was applied through a two-step cluster procedures performed as follows: the rural population of the Gjirokastra Region was divided into four clusters named 1. Cepo, 2. Lunxheri, 3. Picar, and 4. Lazarat. These clusters represent the most important cheese production units of the Gjirokastra region due to the number of breeders and producers. The first three clusters are located in the north of Gjirokastra municipality, while Lazarat is in the south. These units were also selected because they represent the most important units in the region for breeding and cheese production, mainly in hilly and mountainous areas. Then, a subset of respondents within selected clusters was randomly selected and included in the sample. Participants within the clusters were selected using two criteria: the number of ruminants and cheese production for the market. We have considered these two criteria to avoid subsistence farms because: a) their impact on the supply side is limited; b) their decision-making does not impact large producers in their decision to cooperate; c) to create a GI we should start with a limited number of farmers who are more willing to cooperate, have the technical capacities to fulfil the eligibility criteria and meet the regulatory framework required of a GI.

The two-step cluster procedure is applied only for breeders because all cheese producers who use the traditional technique (dairies) have participated in this study. Cheese producers were identified via the database of Agriculture Unit at Gjirokastra Municipality. There are 12 cheese producers in operation in this region, 11 of whom participated in the study, or $91 \%$ of the total population (one cheese producer is intentionally not considered since the production technique does not respect the traditional features of this product)..The breeders' register at the Ministry of Agriculture and Rural Development was accessed regarding the identification and selection of breeders. In total, 101 structured interviews were carried out: 91 breeders and ten cheese producers. About $40 \%$ of the interviews were completed in Cepo, 23\% in Lazarat, $19 \%$ in Lunxheri, and 18\% in Picar. Respondents correspond to the following age groups: $18 \%$ were $25-35$ years old, $15 \%$ were aged $36-45$, $27 \%$ were aged $46-55$, and $40 \%$ were over 55 years old. Concerning respondents' education level, around $51 \%$ have completed high school (12 years), $42 \%$ have elementary education (up to 8 years), and $7 \%$ have a university degree. One of the main problems in the study area is migration and the ageing of the population. We can observe that the majority of the respondents is between 45 years and older. Also, a large part is over 55 years old. On the other hand, young respondents have no interest to settle in this area.

\footnotetext{
${ }^{5}$ The World Bank questionnaire used to map the SC in India in 1999 was adapted for the purposes of this research
} 
Concerning the level of education, our sample is $100 \%$ educated. The majority of the respondents have a medium level of education (have completed 12 years according to the education system in Albania).

How educational level, age-group, profession, and geographical location affect willingness to cooperate is discussed in the following sections.

\section{Data analysis}

Factor Analysis (FA) is used to explore - as the first step - the underlying of elements of the adopted Ostrom Conditions in the case of Gjirokastra Cheese. To identify the symmetric interests,eight observable variables were considered. Four statements under the umbrella: Most users conclude that they will lose profits if they maintain the current rules, and a further four statements under the umbrella of Most users highly value the continuation of the activity (see Appendix, Table 3). The factor analysis allows us to reduce these variables to a smaller set of factors. In this case, it produced two factors; the first represents the perceptions to be harmed (Ostrom Condition 1-OSC1), while the second represents the continuation of the activity perceptions (Ostrom Condition 2 -OSC2). The literature points out two main approaches used to test data validity and in selecting variables for the FA. The Kaiser-Meyer-Olkim (KMO) (1970) test is used to measure the relationship between variables, with the aim of assessing the proportion of variance in selected variables that can be caused by Underlying Factors. It is a measure of sampling adequacy; a test value of greater than 0.5 indicates that the selected variables have sufficient correlation to apply FA (Field, 2009). Bartlett's Test of Sphericity, statistically significant at $1 \%$ level, is used to test the Null hypothesis that the correlation matrix is an index matrix showing that the variables are perfectly independent. In our case, the KMO measure of sampling adequacy is 0.57 and the Bartlet test, with statistically significant P-values $(\mathrm{p}<0.01)$, indicates FA validity.

The second step of analysis uses a binary logit regression to understand whether these two conditions affect willingness to cooperate. Since the dependent variable is binary, the logistic regression model is selected to address the research questions. The empirical model assumes that cooperation probability or willingness to cooperate is dependent on a vector of independent variables $(X i j)$ associated with the respondent $i$ and variable $j$ and a vector of unknown parameters $\beta$. The likelihood of having a given value of dependent variables is tested as a function of variables that included social capital variables such as network, civic engagement, trust, solidarity, reciprocity, perceptions of being harmed, and demographical variables.

$$
P_{i}=F\left(Z_{i}\right)=F\left(\alpha+\beta x_{i}\right)=1 /(1+\exp (-Z i))
$$

where $F(Z i)=$ represents the value of the logistic cumulative density function associated with each possible value of the underlying index. $Z i, P i=$ represents the probability that individuals would be willing to cooperate given the independent variables $X i S, Z i=$ the underlying index number of $\alpha+\beta X i, \alpha=$ intercept, and $\beta X i=$ is the linear combination of the independent variables, so that:

$$
Z i=\log \left[\frac{P i}{(1-P i)}\right]=\alpha i+\beta i 1 X i 1+\beta i X i 2+\ldots \beta i n X i n+\varepsilon i
$$


where $i=1,2 \ldots \mathrm{n}$ are observations, $X n=1,2 \ldots$ explanatory variables $\beta \mathrm{n}=$ parameters to be estimated, $\varepsilon=$ standard error. The following model is developed to evaluate social capital variables, contextual variables, and demographics in willingness to cooperate:

$$
\begin{gathered}
Y=\beta_{0}+\beta_{1} \text { civic engagement }+\beta_{2} \text { network }+\beta \text { trust }+\beta_{4} \text { Solidarity }+\beta 5+ \\
\beta_{6} \text { Ostrom Condition } 1+\beta_{7} \text { Ostrom Condition } 2+\beta_{7} \text { Education }+\beta_{8} \text { Area }+\beta_{9} \text { Age } \ldots . .+\varepsilon
\end{gathered}
$$

where $\mathrm{Y}=$ What would you prefer the most?

- Own and farm 5 hectares of land entirely by themselves (0)

- Own and farm 15 hectares of land jointly with other farmers (1)

Descriptive statistics are also performed to understand social capital, Ostrom condition indicators and demographics considered in this study.

\section{Discussion of results}

To address the first Ostrom Condition, respondents were asked: Are you aware that the name of Gjirokastra Cheese is unfairly applied by the producers of cheese in other regions of Albania? About 93\% stated their awareness of unfair competition due to the usurpation of the name by other producers in other Albanian regions. Regarding the perception of harm caused by name usurpation, respondents did not share the same view; about $50 \%$ stated that name usurpation does not harm them. However, when the following statement was presented, "if we continue with the same rules the benefits would decrease?", $60 \%$ of producers strongly agreed with it. These answers demonstrate that there is no shared perception among local producers concerning urgency regarding business harm by unfair competition. However, they viewed the problem from a time perspective. Almost two out of three respondents were in favour of the government adopting strict management rules. They believe this intervention would protect them since the price paid by the consumer for cheese coming from the Gjirokastra region would not decrease (as happens today in response to the mixed quality of cheese offered by name usurpers). Related to the question, do you think that branding the product will solve name usurpation? About $63 \%$ of respondents said yes, $23 \%$ no, and $14 \%$ did not know. These results show that respondents expect state institutions to take the initiative to protect them, highlighting that they are unable to solve their common problems. The lack of social capital reduces the ability to take action.

The second Ostrom condition, i.e., Most producers highly value the benefits derived from this activity - helped us to understand whether there is potential for the implementation of GI in the case of Gjirokastra Cheese. In this case, we explored whether producers consider that the product has a higher value and higher benefits to justify the continuation of this activity. $62 \%$ of respondents were very satisfied working in the sector, and $80 \%$ reported they would not change this activity even for better pay off in other sectors. Nevertheless, when it comes to considering the involvement of future generations in this activity, the feedback is different: $75 \%$ did not agree with the statement I want my sons and grandsons to be cheese producers and continue this activity. This result is linked with the difficulties currently faced by local producers operating in this sector, and they would prefer their children not to face the same. Similarly, producers perceive that remuneration is low compared to the efforts employed in this activity.

The third Ostrom condition on generalised trust is analysed within the framework of social capital. Where trust is weak, people fail to realise the productivity gains achieved by networks and effective cooperation. About $91 \%$ of respondents felt that in their village/neighbourhood, people generally trust one another in matters of lending. However, 
when it comes to t rusting farmers, only $50 \%$ of respondents shared the same view. Such results were also contemplated by questions that assess the radius of trust i.e. suppose someone from the village/neighbourhood had to go away for a while, along with their family. Who would they ask to take care of their fields? $57 \%$ of respondents reported that they would ask a family member, $25 \%$ the nearest neighbour, while the rest did not know how they would behave in such a situation. The same question was directed intentionally to understand their behaviour: If you suddenly had to go away for a day or two, who could you count on to take care of your children? 55\% would leave their children with their parents or other close family members, while the rest would not leave them at all. These results align with the findings of other authors who maintain that trust exists only in the limited private sphere, not the public domain (Holland, 1998). Howard (2002) argues that this is due to two main reasons: 1) in the high politicisation of the public sphere, many people could express themselves openly only within close circles of trusted friends and family, and 2) during economic shortages, with few available goods to buy or find, connections play an essential role.

According to Realo et al. (2008), a narrow radius of trust and centrality of family, at the expense of excluding the broader society, becomes a hindrance to the free market economy and democratic society. In this vein, Fukuyama (1995) argues that the gradual widening of this radius of trust cannot be accomplished without giving up unquestioning loyalty to the nuclear family and kinship. Community distrust is combined with a lack of trust in state institutions. In 2016, the trust of Albanian citizens in the central government was less than $30 \%$, while the legal system and political parties scored $21 \%$ and $22 \%$, respectively, the lowest performances among former communist countries (IDM 2016) ${ }^{6}$. Distrust of both community members and state institutions is common in other post-communist societies. However, it is higher in Albania since a difficult political-economic transition process further eroded trust in state institutions. Weak trust in social structures and the endemic distrust of post-communist state institutions - particularly after the state collapse of 1997 - hindered the development of cognitive and structural social capital in rural areas.

The last Ostrom condition influencing the establishment of collective action is the existence of a stable group of producers. To understand the degree to which this condition is fulfilled in our study areas, the questionnaire contains the following statement: In the past, the area had fewer producers as today. $42 \%$ of producers strongly disagreed with the statement, $40 \%$ did not know, and $18 \%$ agreed that there is a more significant number of producers. Hence, there is a shared perception that producer numbers are decreasing.

The descriptive analysis based on adapted Ostrom Conditions shows that symmetric interests are negatively affected by limited social capital. The reduced stock of trust hampers the formation of a common narrative and symmetric interests, which reduces willingness to cooperate. The latter, combined with limited trust among community members, undermines the solidity of stakeholders to undertake collective actions (i.e. GI of Gjirokastra Cheese).

Upon completing the analysis concerning the symmetric interests, the paper examines aspects of the study related to structural and cognitive social capital. Analysis of civic participation in the area shows that only $17 \%$ of respondents participate actively in associations such as Farmers Cooperatives, Traders Association, Credit \& Finance Association, Environmental association, and/or other NGOs; $17 \%$ have participated in public protests and drew media attention to a common problem, and $17 \%$ have actively participated in election campaigns. Although $20 \%$ have participated as stakeholders in consultations with local authorities, they considered that they had not influenced the decision-making process. About $50 \%$ of the respondents stated that the leader decides on the behalf of any civic group and just informs its members, while the other half noted that the leader should involve group

${ }^{6} \mathrm{http}: / /$ idmalbania.org/findings-opinion-poll-trust-governance-2017-presented-tirana/ 
members and solicit their opinion before taking decisions. However, only $25 \%$ of respondents considered that their opinions would be considered by the leadership. The feedback also shows a limited capacity to push their civic agenda into the political agenda. Around $40 \%$ of respondents established personal contact with influential persons; however, such contacts can only be set up during election periods. The political candidate usually meets with local actors for electoral platform communication. Afterwards, communication decreases and these contacts are not used for pushing through agendas related to the economic and development aspects of the community. Such results - a) low levels of participation in organisations; b) limited civic activities; c) insufficient involvement in the decision-making process or lobbying to introduce their civic agenda to the political one - all demonstrate a low degree of experience and capacity to initiate, conduct, and push through civic engagement activities.

Moreover, only around $20 \%$ of respondents act as volunteers for a charitable organisation. Lower-income levels, the opportunity cost concerning time ratio and/or limited opportunities to engage in social activities and with charitable organisations might be some of the factors that hinder willingness to participate in community or social activities. Regarding in-kind donations, $45 \%$ of respondents noted that they have participated in such activities in the last five years, while $40 \%$ of respondents contributed to collective investments in the same period of time. However, this result is contradictory to the answers given on the future collective action indicator: $70 \%$ will not contribute to any common investment in their neighbouring area (nearest village in the possible GI area), while $80 \%$ of respondents will not contribute if they do not directly profit from the initiative. This limited degree of participation in community-based activities or community-related investments can be explained as counterreaction to the communist regime experience. The dominance of the Communist ideology, ban on religion, forced structured voluntarism, mandatory membership in state-controlled socio-political organisations, and distrust in local community members are some of the main factors inherited from the authoritarian past, undermining the development of civil society in post-communist Albania. Although this is a phenomenon present in other post-communist states, the radicalisation of state-controlled processes, institutionalised distrust of community members, and religious ban was, however, much more significant in communist Albania, producing as a result, a much more handicapped civil society in the post-communist period. For instance, in a 1994 survey, $75 \%$ of respondents considered that volunteering and trust in community members belonged to the past and was thus irrelevant to future development (OSFA 1994, $)^{7}$. Beyond a limited civic engagement of people, most civil society organisations (CSOs) demonstrate insufficient capacities to realise challenges/perspectives present within the community and possess limited professional/financial resources to make a significant impact. Local CSOs have stronger ties with their communities but possess limited adequate structures, resources, and competencies to interact in a sustainable and meaningful way with decision-makers. A recent report on civil society in Albania and its influence on the decision-making process also shows that CSOs do not apply a proactive approach to build systematic relationships with stakeholders. At the same time, their cooperation with local communities and state institutions is predominantly project-based (Bino et al., 2020).

The indicators related to the network remain contradictory; $90 \%$ of respondents stated that they had shared information with other farmers in their village, and $85 \%$ have shared information with farmers from other villages. Referring to the frequency of meetings, $84 \%$ stated that they meet often and very often, with $80 \%$ agreeing with the statement, Most producers share experiences/knowledge with you.

\footnotetext{
${ }^{7}$ OSFA, Open Society Foundation. 1998. Probleme to pjesmarrjesvullnetare ne shoqerinecivile. [Problems of voluntary participation in civil society.] Tirana: OSFA.
} 
In order to have a clear view on solidarity and willingness towards other community members, respondents answered the following question: Suppose someone in the village faces an unfortunate situation (for example, their home burns down or collapses), in your community, who would be the first to help him/her? About $7 \%$ felt that family members should help, $42 \%$ said people from the village, and $51 \%$ suggested that the institutions in charge s should be responsible. This result is contradictory, as it shows a limited degree of reliance on individualistic behaviour, while the support of community members in need scores almost half in the response rate. This can be explained by the fact that people consider such actions to be an emergency situation with a terrible impact on the community member facing it. This interpretation is contemplated by the degree of respondents who delegate the problem to state institutions. However, this mirrors solidarity in an emergency and cannot be confused and considered contradictory with the previous interpretation according to which the trust relies on narrow circles (usually family circles).

Reciprocity is explored through questions such as: if you face a difficult situation, do you think the inhabitants of the village will help you? About $82 \%$ of respondents agree and strongly agree that inhabitants of the village would help if needed. Related to the statement, the exchange of favours is not among attitudes of your village; $77 \%$ of respondents strongly disagree. This result can be explained by the respondents' perception in assessing their favour to relative to the favour they receive in exchange from other community members. This makes the interpretation of reciprocity in this aspect difficult to evaluate, since usually perceptions reflect what respondents think and not what would be the optimal level of reciprocity.

In terms of previous collective actions, $63 \%$ of respondents stated that farmers have been meeting together a couple of times. Concerning the frequency and regularity of community interaction, $42 \%$ consider that the collective actions of their community have been successful in achieving the proper objective, while more than half, 58\%, consider such community actions as not at all successful. Demonstrating a limited degree of confidence in collective actions as a way to address common challenges. Regarding cooperation with inhabitants of neighbouring villages, about $81 \%$ of participants stated that they have never been asked to address a common issue. This result clearly shows that collective actions have a certain degree of potential success as long as they address issues of interest to the village but fall short in raising interest and participation if other villages are involved. Hence, we can say that for cases such as the GI of the Gjirokastra Cheese, when efficient collective action demands the involvement and cooperation of one or more local communities, neither the awareness nor experience of conducting such actions is in place.

Future collective actions perspective is analysed through indirect questions. For instance: If a project to improve services in the village, from which you will not profit, needs to be financed by the local community, would you contribute? Only $23 \%$ of respondents reported that they would contribute, $69 \%$ would not, and $8 \%$ do not know how they would behave. Following on, respondents were asked, What if your village would not profit from the project, but other villages would profit? Would you then contribute? In this case, $80 \%$ stated that they would not contribute, and only $20 \%$ of respondents would. The results for both questions show a limited willingness to contribute to activities to which they are not directly related or would not extract some profit. In the light of the potential collective action to establish the GI of Gjirokastra Cheese, local producers cannot rely on the entire community's support at large, rather just those who are directly involved (or stakeholders). This result may also induce us to think that respondents are focused on the short-term profit and do not consider that an act of profit for part of the local community will reflect in the mid-to longterm some benefits for members of the community that are not pertinent in the short term period. For instance, community members not directly involved in the profit-chain of cheese 
can hope that in the future, a basket of products or services can be constructed around Gjirokastra Cheese if it becomes a GI product.

The measurement of cognitive social capital and structural social capital offers an overview and some indices on future cooperation levels in the considered community. In order to see how the indicators and willingness to cooperate are related to each other and what component of social capital mostly influences the propensity to cooperate, three binary logits are computed. A comparison of the predicting accuracy of the three tested models shows that the classification percentage is higher when structural social capital is considered (from 60$82 \%$ ) compared to cognitive and symmetric interests. The Wald chi-square tests the null hypotheses that the constant of the model is zero. The null hypothesis is rejected in the three tested models because the p-value is smaller than the critical value p-value 0.05 (see Table 1 ). The goodness of fit of Hosmer-Lemeshow indicates the extent to which the model provides a better fit, the chi-square goodness of fit is not significant in the first two models (it is lower than the critical $\mathrm{p}$ (value $=0.05)$, this is not true in the third model. These results indicate what components of social capital (structural or cognitive) influence willingness to cooperate.

Table 1. Adequacy indicators for the tested logit model

\begin{tabular}{|c|c|c|c|c|c|c|}
\hline \multirow{2}{*}{$\begin{array}{l}\begin{array}{c}\text { Quality of the } \\
\text { model }\end{array} \\
\text { Predicting } \\
\text { accuracy }\end{array}$} & \multicolumn{2}{|c|}{$\begin{array}{c}\text { (1)WTCoop } \\
\text { Structural social capital } \\
\text { +demographics }\end{array}$} & \multicolumn{2}{|c|}{$\begin{array}{c}\text { (2)WTCoop } \\
\text { Cognitive social capital } \\
\text { +demographics }\end{array}$} & \multicolumn{2}{|c|}{$\begin{array}{c}\text { (3) WTCoop } \\
\text { Symmetric interests } \\
\text { +demographics }\end{array}$} \\
\hline & $\begin{array}{l}\text { Intercept } \\
\text { model }\end{array}$ & Model & $\begin{array}{l}\text { Intercept } \\
\text { model }\end{array}$ & Model & $\begin{array}{l}\text { Intercept } \\
\text { model }\end{array}$ & Model \\
\hline & $60.4 \%$ & $82.2 \%$ & $60.4 \%$ & $77.2 \%$ & $60.4 \%$ & $70.3 \%$ \\
\hline \multirow{2}{*}{$\begin{array}{l}\text { Test of model } \\
\text { coefficients }\end{array}$} & Chi-square & $\mathrm{P}$ (value) & Chi-square & $\mathrm{P}$ (value) & Chi-square & $\mathrm{P}$ (value) \\
\hline & 44,090 & 0.000 & 26,094 & 0.002 & 17,361350 & 0.004 \\
\hline \multirow[t]{2}{*}{$\begin{array}{l}\text { Nagelkerke } \\
\text { Pseudo } R^{2}\end{array}$} & $\begin{array}{l}-2 \log \\
\text { likehood } \\
\end{array}$ & $\begin{array}{c}\text { Nagelkerke } \\
\mathrm{R}^{2} \\
\end{array}$ & $\begin{array}{l}-2 \log \\
\text { likehood } \\
\end{array}$ & $\begin{array}{c}\text { Nagelkerke } \\
\mathrm{R}^{2} \\
\end{array}$ & $\begin{array}{l}-2 \log \\
\text { likehood } \\
\end{array}$ & $\begin{array}{c}\text { Nagelkerke } \\
\mathrm{R}^{2} \\
\end{array}$ \\
\hline & 91,527 & 0.47 & 109,523 & 0.30 & 118,256027 & 0.21 \\
\hline \multirow{2}{*}{$\begin{array}{l}\text { Test of } \\
\text { Hosmer- } \\
\text { Lemeshow }\end{array}$} & Chi-square & $\mathrm{P}$ (value) & Chi-square & $\mathrm{P}($ value $)$ & Chi-square & $\mathrm{P}($ value $)$ \\
\hline & 7,908 & 0,443 & 11,529370 &, 173 & 18,128237 & 0,020285 \\
\hline
\end{tabular}

Source: Authors

The pseudo $\mathrm{R}^{2}$ also indicates that the share of the variance is higher when structural social capital variables are considered in the model; the explained variance, in this case, is $47 \%$. The estimation of parameters in the first model shows that respondents participating in information campaigns are 6.5 times more willing to cooperate than those who do not participate. The same holds for the other factors included in the model. Respondents participating in consultation meetings with local authorities and having invested in common community goods are 4.9 and 5.05 times more willing to cooperate than those who have not. Concerning the network variable, the results show that those not sharing information and who do not communicate with the farmers of other villages are less willing to cooperate by a factor of $50 \%$. When considering demographic factors, the odds of cooperation for an additional unit in education are 3.9 times higher, showing that respondents who have achieved a higher level of education are more willing to cooperate than those with less educational accomplishments. 
Indeed, for an additional unit in age level the odds of cooperation are higher by a factor of $63 \%$, meaning that older people are more willing to cooperate than the younger cohort. Concerning the study area; respondents from Lazarat were more willing to cooperate than those from the other regions.

When structural social capital variables are considered, the explained variance in the propensity to cooperate is higher. Respondents participating in information campaigns, consultation meetings with local authorities, having invested in common community goods, and networking with other farmers from other communities are more willing to cooperate than those who have not. These findings align with Putnam's linear approach to social capital. In his social capital discourse, civic engagement is the central pillar of social capital because it is considered the primary source of trust. Hence, with no civic engagement in place, it will be challenging to generate trust. In this vein, in the second logit model are analysed the odds of cooperation when trust indicators are involved

Table 2. The odds of cooperation and the parameter estimation

\begin{tabular}{|c|c|c|c|c|c|c|c|}
\hline \multirow{2}{*}{$\begin{array}{l}\text { The model } \\
\text { Predictor } \\
\end{array}$} & \multicolumn{3}{|c|}{$\begin{array}{l}\text { WTCoop }=\beta_{0}+\beta_{1} \text { civic } \\
\text { engagement } \\
+{ }_{2} \text { network }+\beta_{3} \text { Education } \\
+\beta_{4} \text { Area }+\beta_{5} \text { Age }+\varepsilon\end{array}$} & \multicolumn{4}{|c|}{$\begin{array}{c}\text { WTCoop }=\beta_{0}+\beta_{1} \text { trustcommunity }+\beta_{2} \text { trust } \\
\text { other }+\beta_{3} \text { Institutional trust }+\beta_{4} \text { Reciprocity } \\
+\beta_{5} \text { Solidarity }+\beta_{6} \text { Area }+\beta_{5} \text { Age }+\beta_{5} \text { Education }+\varepsilon\end{array}$} \\
\hline & $\beta$ & Wald & Odd ratio & Predictor & $\mathrm{B}$ & Wald & Odd ratio \\
\hline Area & ,662 & 6,169 & $1,939 * * 8$ & Area &, 021 &, 006 & 1,021 \\
\hline Age & ,491 & 3,116 & $1,633 *$ & Age &, 295 & 1,618 & 1,343 \\
\hline Education & 1,380 & 5,413 & $3,974 * *$ & Education & 1,474 & 9,251 & $4,365 * * *$ \\
\hline $\begin{array}{l}\text { Active } \\
\text { participation in } \\
\text { an information } \\
\text { campaign }\end{array}$ & 1,879 & 4,696 & $6,545^{* *}$ & Trust1 &, 529 & 1,851 & 1,697 \\
\hline $\begin{array}{l}\text { Donation to } \\
\text { community }\end{array}$ & $-1,842$ & 4,384 &, $158 * *$ & $\begin{array}{l}\text { Central } \\
\text { institutional trust }\end{array}$ & ,656 & 5,262 & $1,927 * *$ \\
\hline $\begin{array}{l}\text { Invested in } \\
\text { community }\end{array}$ & 1,620 & 3,996 & $5,056^{* *}$ & $\begin{array}{l}\text { Local } \\
\text { institutional trust }\end{array}$ &, 153 & ,390 & 1,165 \\
\hline $\begin{array}{l}\text { Taken part in a } \\
\text { sit-in or } \\
\text { disruption of } \\
\text { government } \\
\text { meetings }\end{array}$ & 1,608 & 4,312 & $4,990 * *$ & Solidarity &,- 351 & 1,511 & ,704 \\
\hline Network &,- 695 & 3,486 &, $499 *$ & Reciprocity 1 &,- 366 & 1,593 & ,693 \\
\hline- & - & - & - & Reciprocity 2 &,- 010 &, 001 & ,990 \\
\hline
\end{tabular}

Source: Authors

The parameters estimation shows that only institutional trust and education significantly affect willingness to cooperate. Related to the trust variable, trust in state institutions, in your opinion, will the economic and political outlook of the country be better

${ }^{8} \mathrm{P}($ value $) \leq 0.10=*, \mathrm{P}($ value $) \leq 0.05=* *, \mathrm{P}($ value $) \leq 0.01=* * *$ 
or worse, $1=$ better, $2=$ worse, $3=$ do not know), shows a significant effect in willingness to cooperate. Respondents who opted for the worst option are 1.9 times more likely to cooperate than those who think the situation will improve. As in the first model, respondents with a higher level of education are 4.3 times more willing to cooperate than those who have attained a lower level. Thus, respondents with a low level of trust in state institutions and who are more highly educated are more willing to cooperate and undertake collective action initiatives. These results show that when considering willingness to cooperate in addition to social capital construct, demographics and education have, in this case, a significant influence. Highly educated respondents with a low level of trust in state institutions are more willing to cooperate and undertake collective action initiatives because they think that this is the only way to keep their tradition alive and contribute to other local specific activities development. This finding is also important from the policymaking perspective because they are the firsts representatives of the community to embrace innovative territory branding strategies such as GI-s and communicate their advantages effectively to the other community members.

The aim of the third model is to explore if the OSCs has an influence on willingness to cooperate. The Nagelkerke $\mathrm{R}^{2}$ is the lowest, $20 \%$, in this model, showing that these factors do not affect willingness to cooperate ${ }^{9}$. The propensity to cooperate is determined by a local organisation and localised responses to social dilemmas. However, if concern in that social dilemma is not shared among stakeholders, it can no longer be considered as such. The social capital stock has a role to play.

\section{Conclusions}

Gjirokastra cheese producers, who supply a high-quality local product, are exposed to unfair competition and free-riding from other cheese producers who have usurped the brand's name and offered lower quality at the same price. GI legal protection provides an exclusion mechanism that impedes usurpation of product reputation. However, a GI initiative implies shared understandings among local stakeholders regarding risks, priorities, and opportunities since it calls for collective action. Employing the metaphor of matryoshka, this paper provides a set of preconditions that should be in place for collective action to occur. The largest matryoshka contains the need to have a shared narrative around a potential GI. This research explores the existence of a shared narrative around Gjirokastra cheese thanks to two main dimensions: a) stakeholder perception of being harmed if not using the GI mechanism; and b) their commitment to continue this activity in the future. The results of the study, however, show that both perceptions are not shared by all producers (stakeholders), which undermines the process of creating a common narrative. Components of cognitive social capital examined in this paper - lower trust in state institutions and limited reciprocity among producers - can explain the reduced stock of social capital, which in turn hampers the formation of a common narrative and symmetric interests. The lack of a common narrative shows no cause effect relationship between the perceptions of being harmed by unfair competitiveness and willingness to cooperate in creating a GI to address this challenge.

Exploring the causes of the lack of common narrative brings us to the second largest matryoshka, i.e. willingness to cooperate and undertake collective action among local stakeholders. Regarding willingness to cooperate, the empirical data illustrates Putnam's linear relationship showing that participation in civil society organisations (CSOs) roots among members a cooperative attitude. The low levels of membership and participation in CSOs in the local area follow the same pattern as in other post-Communist rural areas.

\footnotetext{
${ }^{9}$ The table of the parameter coefficient is not presented since none of the Ostrom Conditions show a significant effect.
} 
However, respondents participating in information campaigns, local government consultation meetings, and investing in common community causes - either in kind or financially - are more likely to cooperate than those who have not. Respondents who do not interact or communicate with farmers in neighbouring communities are less willing to cooperate. The effect of structural social capital in willingness to cooperate adds to the negative effect of cognitive social capital.

However, the study has shown that when analysing willingness to cooperate, demographic factors and education require particular attention since they can influence the effects of the former communist legacy. This influence is essential regarding the elements of the smallest matryoshka, i.e. trust and reciprocity. During the communist regime, the ban on religion, rooted distrust in other community members, forced membership of state-controlled organisations, forced collectivisation in agricultural production - which promoted selfishness and individualism as a counter-reaction - constitute a legitimacy of the past which, combined with distrust of current state institutions, explains the low levels of trust and reciprocity among stakeholders illustrated by the study. Hence, to start addressing these pitfalls, the study identifies - by employing demographic and educational features as discriminatory elements the stakeholder group that is more ready to cooperate and the cohort that needs more awareness about the importance of cooperation. The study shows that better-educated respondents are more willing to cooperate than those who have lower levels of education. As in other post-communist countries, the education and demographic factors can become an important element that may help overcome the negative perceptions of cooperation from the past.

However, the lack of a common narrative and limited willingness to engage in collective action, fuelled by low levels of trust and reciprocity among local stakeholders, demonstrates that Gjirokastra Cheese producers are not yet convinced, nor ready to undertake the collective actions necessary to establish a GI on their well-reputed local product.

Beyond the interesting findings concerning the readiness of local stakeholders to create a GI on the Gjirokastra Cheese, this ex-ante study provides an analytical model employable to assess the willingness of local stakeholders to cooperate in achieving a common goal in other post-communist rural areas. The proposed model combines operationalised, cognitive and structural, social capital indicators with Ostrom Conditions on collective action. Some Ostrom conditions, such as shared understanding of the risks of collective action, are not undertaken. The worthiness of continuing such activity provides the symmetric interests, constituting the preconditions or preliminary incentives (common narrative) to ensure that the willingness to participate in collective action can materialise. At the same time, the Ostrom condition on trust and reciprocity constitutes, in the analytical model, the transition from the factors that need to pre-exist to those factors that should be analysed as components of cognitive social capital.

The economic potential of this paper stands on identifying the missed opportunities of the economic development in this area as the result of the non-application of the GIs mechanisms. It offers a clear cause-effect explanation of how social factors such as the lack of a narrative and shared trust hinder the collective actions necessary for implementing economic mechanisms - such as GI - to promote local development. A quick understanding of this missed opportunity becomes apparent when comparing the development of this region with similar regions - in terms of climate and geographical conditions - in nearby Greece, where the GI component remains a crucial factor in enhancing these rural areas' development. 


\section{Acknowledgement}

This research was financially supported by SMART-AL (Master in European Innovation for Sustainable Management of Albanian Territories, Rural Areas: Instruments, Policies, Strategies and Agriculture) Erasmus+ Capacity Building Project, no 586405-EPP-12017-1-FR-EPPKA2-CBHE-JP (2017-2977/001-001).

\section{References}

Alvarez, E. C., \&Romai, J. R. (2017). Measuring Social Capital: further insights. Gaceta Sanitaria, 31(1), 57-61.

Bino, B., Qirjazi, Redion, \&Dafa, Alban (2020). Pjesëmarrja e Shoqërisë Civilenë Vendimmarrjenë Shqipëri (p. 58). Westminster Foundation for Democracy.

Bowles, S., \& Gintis, H. (2002). Social Capital and Community Governance. The Economic Journal, 112(483), F419-F436. https://doi.org/10.1111/1468-0297.00077

Brehm, J., \& Rahn, W. (1997). Individual-Level Evidence for the Causes and Consequences of Social Capital. American Journal of Political Science, 41(3), 999.

Callois, J. M. (2004). Social Capital and Local Economic Development: An application to French rural areas. Revue D`Economie Regionale et Urbaine, 4, 551-578.

Callois, J. M., \& Aubert, F. (2007). Towards Indicators of Social Capital for Regional Development Issues: The Case of French Rural Areas. Regional Studies, 41(06), 809-821.

Dowley, K. M., \& Silver, B. D. (2002). Social Capital, Ethnicity and Support for Democracy in the Post-Communist States. Europe-Asia Studies, 54(4), 505-527. https://doi.org/10.1080/09668130220139145

Villalonga-Olives, E., \& Kawachi, I. (2017). The dark side of social capital: A systematic review of the negative healtheffects of social capital. Social Science and Medicine, 194, 105-127.

Frey, B. S., \& Bohnet, I. (1996). Cooperation, communication and communitarianism: an experimental approach.4(4), 322-336.

Gardner, R., Ostrom, E., \& Walker, J. M. (1990). The Nature of Common-Pool Resource Problems. Rationality and Society, 2(3), 335-358. https://doi.org/10.1177/1043463190002003005

Gatzweiler, F., \& Hagedorn, K. (2001). The evolution of institutions in transition. https://www.ssoar.info/ssoar/handle/document/38726

Groote, U. (2009). Environmental Labeling, Protected Geographical Indications and the Interests of Developing Countries. Estey Journal of International Law and Trade Policy, 10(1), 94-110.

Guri, F. (2008). Marché et politiques foncières dans la zone littorale Albanaise: le cas de la zone Durrës-Kavaja. SupAgro.

Guri, F., Civici, A., \& Jouve, A. M. (2011). Est-ce que l'extrême égalité sociale est un objectif à atteindre? Le cas des réformes agraires en Albanie. New Medit, 10(1), 25-34.

Harpham, T., Grant, E., \& Thomas, E. (2002). Measuring social capital within health surveys: key issues. Health Policy and Planning, 17(1), 106-111.

Helliwell, J. F., \& Putnam, R. D. (1995). Economic Growth and Social Capital in Itali. Eastern Economic Journal, 21(3), 295-307. See: https://econpapers.repec.org/article/eejeeconj/v_3a21_3ay_3a1995_3ai_3a3_3ap_3a295307.htm

Hirczak, M., Moalla, M., Mollard, A., Pecqueur, B., Rambonilaza, M., \&Vollet, D. (2008). From the Basket of Goods to a More General Model of Territorialized Complex Goods: Concepts, Analysis Grid and Questions. Canadian Journal of Regional Science, 31(2). See: https://go.gale.com/ps/anonymous?id=GALE\%7CA204985880\&sid=googleScholar\&v=2.1\&i $\mathrm{t}=\mathrm{r} \&$ linkaccess $=\mathrm{abs} \& \mathrm{issn}=07054580 \& \mathrm{p}=\mathrm{AONE} \& \mathrm{sw}=\mathrm{w}$

Holland, J. (1998). Does Social Capital Matter? The Case of Albania. IDS Bulletin, 29(3), 65-71.

Howard, M. M. (2002). The Weakness of Postcommunist Civil Society. Journal of Democracy, 13(1), 157-169. https://doi.org/10.1353/jod.2002.0008 
Irwin, K., \& Berigan, N. (2013). Trust, Culture, and Coperation: A Social Dilemma Analysis of ProEnvironmental Behaviors. 54(3), 424-449.

Kokthi, E., Bermúdez, I. V., \& Limón, M. G. (2016). Predicting willingness to pay for geographical origin in Albania: A logistic approach. New Medit, 15(2), 63-69.

Kokthi, E., \&Kruja, D. (2017). Consumer Expectations for Geographical Origin: Eliciting Willingness to Pay (WTP) Using the Disconfirmation of Expectation Theory (EDT). Journal of Food Product Marketing, 23(8), 873-889.

Kunioka, T., \& Woller, G. M. (1999). In (a) democracy we trust: Social and economic determinants of support for democratic procedures in central and eastern Europe. The Journal of SocioEconomics, 28(5), 577-596. https://doi.org/10.1016/S1053-5357(99)00035-9

Murray, C. (2005). Social capital and cooperation in Central and Eastern Europe: a theoretical perspective.

Notaro, S., \& Paletto, A. (2011). Links between Mountain Communities and Environmental Services in the Italian Alps. 51(2), 137-157. See: https://onlinelibrary.wiley.com/doi/abs/10.1111/j.14679523.2011.00532.x

Ostrom, E. (1990). Coping with Tragedies of the Commons. 2, 493-535.

Ostrom, E. (2000). Reformulating the Commons. Swiss Political Science Review, 6(1), 29-52. https://doi.org/10.1002/j.1662-6370.2000.tb00285.x

Ostrom, E. (2003). Toward a Behavioral Theory Linking Trust, Reciprocity,and Reputation. In Trust and Reciprocity, Interdisplinary lessons from experimental research (pp. 19-79).

Ostrom, E. (2011). Background on the Institutional Analysis and Development Framework: Ostrom: Institutional Analysis and Development Framework. Policy Studies Journal, 39(1), 7-27. https://doi.org/10.1111/j.1541-0072.2010.00394.x

Pacciani, A., Belletti, G., Marescotti, Andrea, \& Scaramuzzi, Silvia (2001). The Role of Typical Products in Fostering Rural Development and the Effects of Regulation (eec) 2081/92. Policy Experiences with Rural Development in a Diversified Europe. 73rd Seminar of the European Association of Agricultural Economists, Ancona.

Paldam, M., \& Svendsen, G. T. (2000). An essay on social capital: Looking for the fire behind the smoke. European Journal of Political Economy, 16(2), 339-366. https://doi.org/10.1016/S0176-2680(99)00064-6

Pecqueur, B. (2001). Quality and territorial development. The hypothesis of the basket of goods and services territorialized. Rural Economy, 261, 37-49.

Putnam, R. (1993). The Prosperous Community Social Capital and Public Life. The American Prospect, 13(4).

Putnam, R. (2000). Bowling Alone: America's Declining Social Capital. Culture and Politics, 223234.

Rangekar, D. (2004). The socio-economics of geographical indications. (UNCTAD-ICTSD Project on IPRs and Sustainable Development, pp. 13-15).

Realo, A., Allik, J., \& Greenfield, B. (2008). Radius of Trust: Social Capital in Relation to Familism and Institutional Collectivism. Journal of Cross-Cultural Psychology, 39(4), 447-462. https://doi.org/10.1177/0022022108318096

Rothstein, B., \& Stolle, D. (2008). The State and Social Capital. An Institutional Theory of Generalized Trust. 40(4), 441-459.

Shiell, A., Hawe, Penelope, \& Kavanagh, S. (2018). Evidence suggests a need to rethink social capital and social capital interventions. Social Science and Medicine.

Villalonga-Olives, E., Adams, I., \& Kawachi, I. (2016). The development of a bridging social capital questionnaire for use in population health research. SSM - Population Health, 2, 613-622. https://doi.org/10.1016/j.ssmph.2016.08.008

Villalonga-Olives, E., \& Kawachi, I. (2015). The measurement of bridging social capital in population health research. Health \& Place, 36, 47-56. https://doi.org/10.1016/j.healthplace.2015.09.002

Welter, F. (2012). All we need is trust?A critical review of the trust and entrepreneurship literature. International Small Business Journal, 30(3), 193-212. 


\section{Appendix}

Table 3. Ostrom conditions and cognitive social capital

\begin{tabular}{ll}
\hline Items of analysis & Statement of scenarios - questions \\
\hline OSTROM Condition 1 & Most farmers conclude that they will lose profits if they
\end{tabular}
maintain the current value

1. The use of the name by the other producers has resulted in significant harm to the product's reputation. ( $1=$ harmed a lot, $5=$ not harmed at all)

2. Most producers and breeders conclude that they will lose if rules are not adopted. $(1=$ strongly disagree, $5=$ strongly agree)

3. If we continue with the same rules, benefits will decrease. $(1=$ decrease a lot, $5=$ increase a lot $)$

4. You are in favour of the adaption of strict management rules by the government. ( $1=$ strongly disagree, $5=$ strongly agree)

5. The branding of the product will solve the problem of usurpation. ( $1=$ strongly disagree, $5=$ strongly agree)

\section{OSTROM Condition 3}

OSTROM Condition 4 generalised norms of trust are analysed through the cognitive component of social capital
Most users highly value the continuation of the activity

1. All things considered, how satisfied are you working within this sector related to cheese in most dairy products. $(1=$ not at all satisfied, $5=$ very satisfied $)$

2. I want my son to be a cheese producer. $(1=$ strongly disagree, $5=$ strongly agree)

3. I want my son and grandson to be cheese producers. ( $1=$ strongly disagree, $5=$ strongly agree $)$

4. I want to stop this activity if I find a job with a better salary. (1=strongly disagree, 5=strongly agree)

\section{Generalised norms of trust}

1. If you have to leave the village for some time, who will you ask to take care of the house?

- Family members (parents, brother, sister)

- Neighbours

- Anyone from the village/neighbourhood

- No one

- Others (specify)

2. If you suddenly have to go away for a day or two, who could you count on to take care of your children?

- Family members (parents, brother, sister)

- Neighbours

- Anyone from the village/neighbourhood

- I don't have children

\section{Trust in institution}

1. In your opinion, will the economic and political outlook of the country be better or worse? $(1=$ better, $2=$ worse, $3=$ I don 't know) 
Table 4. Structural social capital

\begin{tabular}{cl}
\hline Structural social capital components & Statement of scenarios - questions \\
\hline 1. Civic engagement & Participation in organisations
\end{tabular}

1. Are you or someone from your family a member of any organisation? Yes/no

2. If yes, which type of organisation.

3. Is it a national, regional or local organisation?

4. In the last five years, have you personally done any of the following things;

- Voted? Yes/no

- Participated in demonstration or strike? Yes/no

- Spoken with the media about a common problem? Yes/no

- Made personal contact with an influential person? Yes/no

- Actively participated in an information campaign? Yes/no

- Taken part in a sit-in or disruption of government meeting/office? Yes/no

2. Network

1. Do you share information with other farmers in the same village? Yes/no

2. Do you share information with other farmers of other villages? Yes/no

3. How often do you meet other farmers? (1=very rarely,5=very often)

3. Previous collective actions

1. How often have members of this village/neighbourhood come together and jointly petitioned government officials or political leaders, with village development as their goal in the past years? $(1=$ very rarely, $5=$ very often $)$

2. Was this action/ were these actions successful?

- Yes, all were successful

- $\quad$ Some of them were successful, and others not

- Non, none were successful

3. How often in the past year have you joined together with others in the village/neighbourhood to address a common issue? $(1=$ very rare, $5=$ very often $)$

\section{Future collective actions Willingness to participate in collective actions}

1. If a project to improve service in the village, from which you will not profit, needs to be financed by the local community, would you contribute? (Yes, no, I do not know)

2. What if your village does not profit, but it will benefit other villages? Would you contribute? (yes, no, I do not know) 